\title{
INOVASI PRODUK KUE DALAM MEMPERTAHANKAN SIKLUS HIDUP PADA PERUSAHAAN AMANDA BROWNIES
}

\author{
Nadya Cahya Umi Mashita ${ }^{1}$, Joko Widodo ${ }^{1}$, Mukhamad Zulianto ${ }^{1}$ \\ Pendidikan Ekonomi, Fakultas Keguruan dan Ilmu Pendidikan, Universitas Jember \\ E-mail:nadyacahya9@gmail.com
}

\begin{abstract}
Abstrak
Penelitian ini bertujuan untuk mendeskripsikan inovasi produk kue dalam mempertahankan siklus hidup pada perusahaan Amanda Brownies. Penelitian ini merupakan penelitian deskriptif dengan pendekatan kualitatif. Subjek dalam penelitian ini adalah manager kantor Amanda Brownies cabang Jember, sedangkan informan penelitian yaitu karyawan dan konsumen Amanda Brownies cabang Jember. Metode pengumpulan data yang digunakan yaitu metode wawancara, observasi dan dokumentasi. Metode Analisis data yang digunakan yaitu tahap reduksi data, penyajian data dan penarikan kesimpulan. Hasil penelitian ini menunjukkan bahwa perusahaan Amanda Brownies melakukan inovasi produk kue dalam mempertahankan siklus hidup produknya. Inovasi produk yang dilakukan perusahaan Amanda Brownies yaitu inovasi berbasis modulasi, inovasi berbasis kemasan, inovasi berbasis desain dan inovasi berbasis pengembangan bahan komplementer. Dengan adanya inovasi produk kue yang dilakukan perusahaan Amanda Brownies mampu mempertahankan siklus hidup produknya sehingga perusahaan Amanda Brownies sampai saat ini masih berada pada tahap pertumbuhan dan tetap bertahan sampai saat ini dengan wilayah pemasaran yang semakin luas hampir di seluruh kota di Indonesia seperti Jember, Situbondo, dan Lumajang meskipun saat ini banyak perusahaan pesaing yang memproduksi produk sejenis.
\end{abstract}

Kata Kunci: Inovasi Produk, Siklus Hidup Produk

\section{PENDAHULUAN}

Perkembangan dunia usaha kue di Indonesia semakin berkembang pesat. Hal tersebut tentu menyebabkan kalangan usaha saling berlomba untuk mendapatkan keunggulan kompetitif. Dengan banyaknya perusahaan kue yang bermunculan, tentu saja pemilik perusahaan dituntut agar selalu memiliki keunggulan untuk produk yang diciptakan dibandingkan dengan pesaingnya. Diharapkan dari keunggulan yang dimiliki, akan menarik banyak konsumen yang nantinya membawa perkembangan yang positif bagi kelangsungan hidup perusahaan sehingga tetap bertahan dipasaran.

Salah satu upaya yaang dapat dilakukan perusahaan dalam menghadapi persaingan yang semakin ketat yaitu melalui inovasi dengan menciptakan produk atau memodifikasi produk yang sudah ada agar memiliki nilai lebih dimata konsumen. Inovasi merupakan salah satu kunci untuk memenangkan persaingan yang nantinya perusahaan bisa mencapai keunggulan kompetitif sehingga kelangsungan hidup perusahaan dapat bertahan dalam jangka panjang (Hendrayanti,2011:97),

Dalam persaingan industri kue, kue brownies banyak diminati oleh konsumen sehingga permintaan pasarnya semakin meningkat. Kue ini sangat disukai konsumen dari berbagai usia baik muda maupun tua (Indriani,2006:3). Hal ini membuat semakin banyak perusahaan kue brownies yang bermunculan. Salah satu perusahaan brownies yang terkenal di Indonesia yaitu perusahaan Amanda Brownies. Amanda Brownies adalah salah satu pelopor yang memperkenalkan brownies di Indonesia yang memiliki ciri khas dengan kualitas produk yang tinggi dan menjadi leader dengan tetap mempertahankan, memperbaiki dan terus mengembangkan kualitas produknya.

Brownies hasil produk dari perusahaan Amanda Brownies memiliki tekstur yang lebih lembut dibandingkan dengan brownies yang diproduksi perusahaan lain. Selain itu varian rasa brownies Amanda lebih beragam dibandingkan dengan perusahaan lain. Varian rasanya antara lain rasa cheese cream, sarikaya pandan, blueberry, strawberry, tiramisu, banana bizz, banana cheese, choco marble, pink marble, tiramisu marble, strawberry cheese, lemon cheese, green tea mint, cappucino marble dan green marble.

Inovasi brownies yang digagas oleh perusahaan Amanda Brownies terdiri dari berbagai varian 
jika tetap dipertahankan dan dilakukan pembaharuan akan menarik banyak konsumen sehingga perusahaan bisa mencapai keunggulan kompetitif dan kelangsungan hidup perusahaan dapat bertahan dalam jangka panjang. Berdasarkan penjelasan diatas, peneliti melakukan penelitian yang bertujuan untuk mendeskripsikan inovasi produk kue dalam mempertahankan siklus hidup pada perusahaan Amanda Brownies.

\section{METODE}

Penelitian ini menggunakan jenis penelitian deskriptif dengan pendekatan kualitatif. Lokasi penelitian ini dilaksanakan di kantor Amanda Brownies cabang Jember yang terletak di Jl. Gajah Mada No. 146 Jember. Penentuan lokasi penelitian ini menggunakan metode purposive area yaitu lokasi penelitian yang ditentukan secara sengaja. Pertimbangan peneliti memilih perusahaan Amanda Brownies karena perusahaan Amanda Brownies selalu menciptakan ide-ide baru dalam produknya. Perusahaan Amanda Brownies juga teliti dalam membaca peluang, artinya mereka bisa menciptakan brownies yang sesuai dengan permintaan konsumen.

Subjek dalam penelitian ini adalah manager kantor Amanda Brownies cabang Jember, sedangkan Informan tambahan yaitu karyawan dan konsumen Amanda Brownies cabang Jember. Metode pengumpulan data yang digunakan terdiri dari metode wawancara, observasi, dan dokumentasi. Analisis data yang digunakan yaitu reduksi data, penyajian data, dan penarikan kesimpulan.

\section{HASIL DAN PEMBAHASAN \\ Hasil Penelitian}

Inovasi yang dilakukan oleh perusahaan Amanda Brownies pada produk browniesnya untuk memenuhi kebutuhan dan keinginan konsumen yang berubah dan untuk memenangkan persaingan pasar. Pada awalnya brownies yang diproduksi oleh perusahaan Amanda Brownies hanya rasa original tanpa ada campuran rasa lain namun setelah melakukan inovasi maka banyak berbagai varian rasa brownies yang diproduksi oleh Amanda Brownies. Inovasi yang dilakukan oleh Amanda Brownies adalah inovasi berbasis modulasi, inovasi berbasis kemasan, inovasi berbasis desain, inovasi berbasis pengembangan bahan komplementer.

\section{Inovasi Berbasis Modulasi}

Inovasi berbasis modulasi merupakan pengubahan karakteristik produk dengan menaikkan atau menurunkan karakteristik produk. Secara umum mengacu pada karakteristik fungsional atau fisik. Karakteristik ini lebih mengarah pada rasa yang dimiliki oleh brownies. Modulasi yang dipilih yaitu dengan menaikkan karakteristik dasar, menaikkan yang dimaksud disini yaitu berupa penambahan berbagai macam varian rasa brownies. Awalnya rasa yang dimiliki hanya original namun Amanda Brownies mulai menambahkan berbagai macam varian lain kedalam brownies yang diproduksinya. Penambahan varian rasa yang dilakukan antara lain rasa cheese cream, sarikaya pandan, blueberry, strawberry, tiramisu, banana bizz, banana cheese, choco marble, pink marble, tiramisu marble, strawberry cheese, lemon cheese, green tea mint, cappucino marble dan green marble.

\section{Inovasi Berbasis Kemasan}

Kemasan merupakan wadah atau tempat yang dapat melindungi produk yang berada didalamnya, disamping itu melindungi dari bahaya pencemaran yang dapat membuat produk menjadi rusak. Pada awalnya kemasan yang digunakan sebagai pembungkus brownies Amanda yaitu menggunakan kotak kemasan atau dus berbentuk persegi panjang dengan ukuran $24.5 \times 12 \mathrm{~cm} \times 7 \mathrm{~cm}$. Namun seiring berjalannya waktu, perusahaan Amanda Brownies mulai menambah kotak kemasan yaitu kotak kemasan snack box. Kemasan snack box brownies Amanda memiliki ukuran lebih kecil dibandingkan kotak Amanda Brownies sebelumnya.

\section{Inovasi Berbasis Desain}

Inovasi berbasis desain merupakan inovasi produk yang mengubah tampilan atau memodifikasi produknya. Desain yang digunakan pada brownies Amanda yaitu desain berlapis namun hanya untuk brownies dengan varian rasa tertentu, misalnya untuk varian rasa cheese cream, sarikaya pandan, blueberry, strawberry, tiramisu, banana cheese, strawberry cheese, lemon cheese, green tea mint. Sedangkan untuk brownies dengan rasa original tanpa campurn buah menggunakan desain polos 
karena untuk menjaga kemurnian warna brownies dan tidak merubah rasa asli coklat brownies.

\section{Inovasi Berbasis Pengembangan Bahan Komplementer}

Inovasi berbasis pengembangan bahan komplementer ini melibatkan penambahan bahan-bahan komplementer (tambahan) kedalam produk dasar untuk menciptakan varian rasa produk. Pengembangan bahan komplementer yang dilakukan perusahaan Amanda Brownies untuk menciptakan kue brownies dengan berbagai varian rasa dan menghasilkan kue brownies yang berkualitas.

Pengembangan bahan komplementer yang dilakukan perusahaan Amanda Brownies dalam menciptakan varian rasa terbaru menggunakan bahan-bahan yang sederhana. Untuk menghindari penggunaan bahan pengawet perusahaan Amanda Brownies menambahkan bahan pelengkap yang terbaik seperti keju, kismis dan kacang almond.

\section{Siklus Hidup Produk (Product Life Cycle)}

Siklus hidup produk merupakan tahap-tahap yang dilalui suatu produk yang benar-benar baru dari awal hingga akhir yang harus dipahami oleh setiap perusahaan untuk memproduksi dan memasarkan produknya agar mampu bertahan dan bersaing dengan perusahaan lain.

Siklus hidup perusahaan Amanda Brownies saat ini masih berada pada siklus hidup tahap pertumbuhan (growth), tahap ini ditandai dengan produk Amanda Brownies yang semakin lama semakin diminati oleh konsumen dan penjualan perusahaan selalu mengalami peningkatan setiap tahunnya meskipun saat ini banyak perusahaan pesaing yang memproduksi produk sejenis. Perusahaan Amanda Brownies selalu berusaha mempertahankan agar produknya tetap berada pada tahap pertumbuhan (growth) sehingga tidak mengalami tahap penurunan (decline).

\section{Inovasi Produk Dalam Mempertahankan Siklus Hidup Produk}

Inovasi produk merupakan suatu langkah yang dilakukan perusahaan untuk memperpanjang siklus hidup produknya pada saat produk mencapai tahap pertumbuhan (growth) dan tahap kedewasaan (maturity). Untuk mendapatkan hasil yang maksimal tentu saja inovasi yang dilakukan harus bertahap seperti yang dilakukan perusahaan Amanda Brownies. Berikut adalah tabel yang menjelaskan inovasi produk yang dilakukan oleh perusahaan Amanda Brownies untuk memperpanjang siklus hidup produk (product life cycle) agar produk tidak mengalami tahap penurunan (decline).

Tabel 1. Inovasi Produk Dalam Upaya Mempertahankan Siklus Hidup Produk

\begin{tabular}{|c|c|c|}
\hline Tahun & Inovasi Produk & Pasar \\
\hline 2016 & $\begin{array}{l}\text { 1. Inovasi Berbasis Modulasi : } \\
\text { 1) Original } \\
\text { 2) Cheese cream } \\
\text { 3) Sarikaya pandan } \\
\text { 4) Blueberry } \\
\text { 5) Strawberry } \\
\text { 6) Tiramisu } \\
\text { 7) Banana bizz } \\
\text { 8) Banana cheese } \\
\text { 9) Chocho marble } \\
\text { 10) Pink Marble } \\
\text { 11) Tiramisu marble } \\
\text { 12) Strawberry cheese } \\
\text { 13) Lemon cheese } \\
\text { 14) Bolu pandan } \\
\text { 15) Brownies bakar } \\
\text { 16) Brownies kering. }\end{array}$ & Jember \\
\hline
\end{tabular}


2. Inovasi Berbasis Kemasan :

1) Kemasan kotak

3. Inovasi Berbasis Desain :

1) Polos

2) Berlapis

4. Inovasi Berbasis Pengembangan Bahan Komplementer :
1) Sarikaya
2) Blueberry
3) Strawberry
4) Pisang
5) Coklat tiramisuu
6) Keju
7) Ekstra pandan
8) Ekstra Lemon

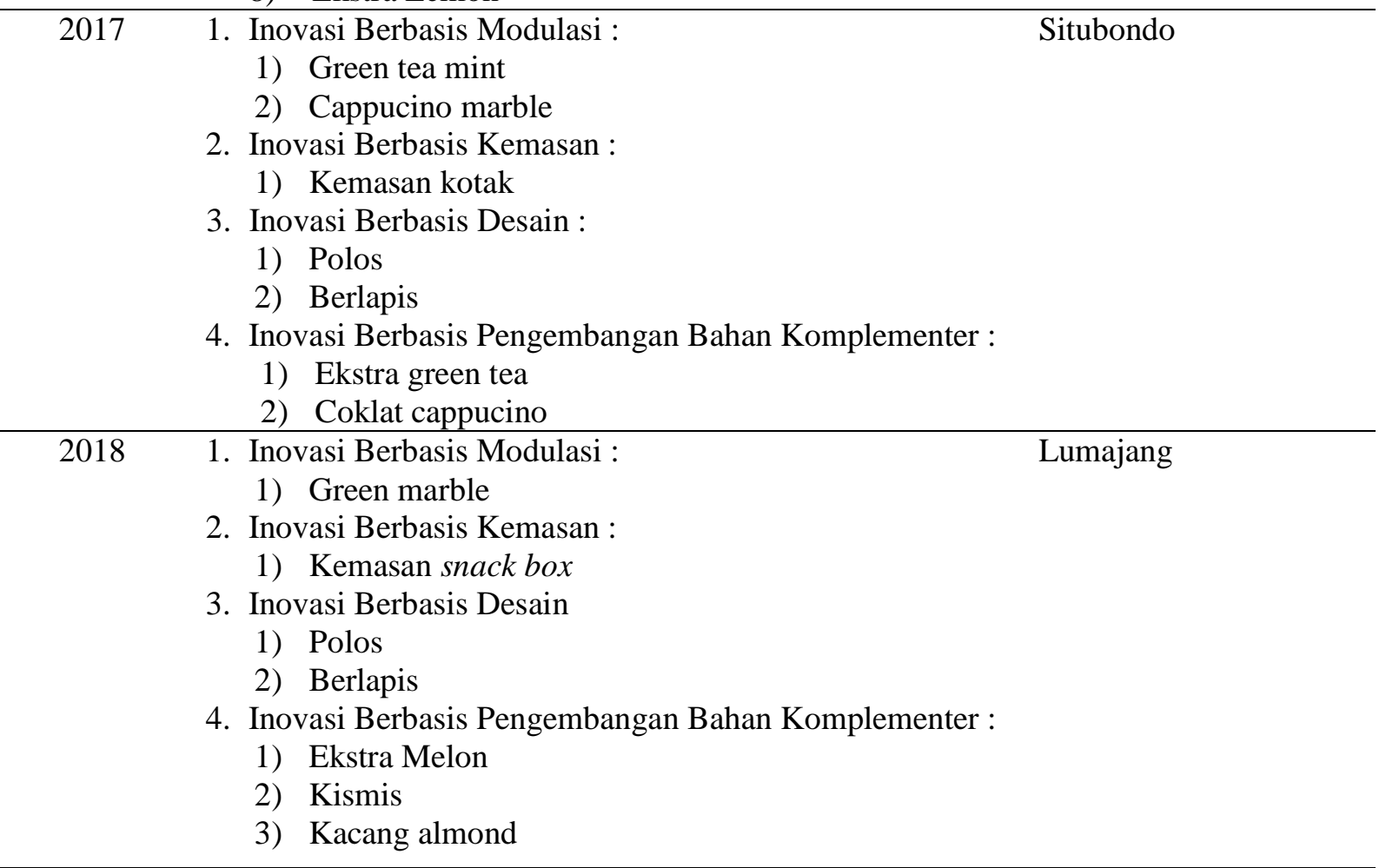

Sumber: Amanda Brownies Cabang Jember (2018)

Pada tabel diatas dapat dijelaskan bahwa perusahaan Amanda Brownies selalu melakukan inovasi secara bertahap dan berkelanjutan untuk memperpanjang siklus hidup produknya agar tidak mengalami tahap penurunan (decline) dan tetap bertahan dipasaran. Inovasi produk yang dilakukan perusahaan Amanda Brownies secara bertahap dan berkelanjutan nyatanya dapat memperpanjang siklus hidup perusahaan sehingga perusahaan tetap berada pada tahap pertumbuhan ( growth) dan tetap bertahan sampai saat ini dengan wilayah pemasaran yang semakin luas hampir di seluruh kota-kota di Indonesia seperti kota Jember, Situbondo dan Lumajang.

\section{Pembahasan}

Hasil penelitian ini menunjukkan bahwa perusahaan Amanda Brownies melakukan inovasi produk dalam mempertahankan siklus hidup produknya. Dalam penelitian ini inovasi produk pada perusahaan Amanda Brownies yang diteliti meliputi inovasi berbasis modulasi, inovasi berbasis kemasan, inovasi berbasis desain, dan inovasi berbasis pengembangan bahan komplementer. Dengan adanya inovasi produk yang dilakukan diharapkan dapat memperpanjang siklus hidup produk 
perusahaan Amanda Brownies sehingga tidak mengalami tahap kemunduran (decline) agar tetap bertahan dipasaran.

Inovasi pertama yang dilakukan oleh perusahaan Amanda Brownies adalah inovasi berbasis modulasi. Inovasi modulasi yang dilakukan perusahaan Amanda Brownies yaitu menaikkan karakteristik dasar produknya dengan cara mengubah varian rasa brownies yang ada menjadi berbagai macam varian rasa terbaru. Hal ini sesuai dengan pendapat Kotler dan De Bes (2004:31) inovasi berbasis modulasi yaitu inovasi yang dilakukan perusahaan dengan melibatkan pengubahan suatu karakteristik dasar produk atau jasa, dengan cara menaikkan atau menurunkan karakteristik tersebut. Secara umum, mengacu pada karakteristik-karakteristik fungsional atau dasar.

Pada awal produksi perusahaan Amanda Brownies hanya memproduksi brownies dengan rasa original. Namun seiring berjalannya waktu, perusahaan Amanda Brownies melakukan penambahan varian rasa pada brownies yang diproduksinya menjadi berbagai macam varian rasa, seperti rasa brownies cheese cream, sarikaya pandan, blueberry, strawberry, tiramisu, banana bizz, banana cheese, chocho marble, pink marble, tiramisu marble, strawberry cheese, lemon cheese, bolu pandan, brownies original bakar, brownies kering, green tea mint, cappuccino marble, green marble.

Inovasi kedua yang dilakukan perusahaan Amanda Brownies yaitu inovasi berbasis kemasan. Kemasan merupakan tempat yang digunakan sebagai pembungkus produk. Pada awal produksi, kemasan yang digunakan perusahaan Amanda Brownies yaitu kemasan kotak (dus). Namun seiring waktu berjalan perusahaan Amanda Brownies mulai menambah kemasan lain yaitu kemasan snack box. Kemasan snack box ini merupakan kemasan khusus untuk pemesanan acara-acara tertentu seperti acara tasyakuran, rapat dan arisan. Hal ini sesuai dengan pendapat yang disampaikan oleh Kotler dan De Bes (2004:31) inovasi berbasis kemasan didasarkan bagaimana cara sebuah produk dikemas sehingga dapat mengubah persepsi konsumen mengenai manfaat, fungsi, atau alasan konsumsi dari produk atau jasa.

Inovasi ketiga yang dilakukan perusahaan Amanda Brownies yaitu inovasi berbasis desain. Inovasi desain yang dilakukan perusahaan Amanda Brownies dengan mengubah desain tampilan brownies yang diproduksinya saja tanpa merubah isi dan ukuran produk brawnies yang di produksi. Awal peluncuran produk hanya menggunakan desain polos tanpa campuran warna dan motif lain. Hal ini dikarenakan persepsi konsumen yang menganggap bahwa brownies hanya cocok dengan tampilan yang original. Mungkin akan terasa aneh jika diberikan varian rasa lain selain original. Namun seiring berjalannya waktu maka tampilan brownies yang sudah ada dimodifikasi dengan cara menambah motif lain yaitu motif berlapis. Motif yang digunakan ini antara lain ada yang 2 lapis dan 3 lapis. Hal ini sesuai dengan pendapat Kotler dan De Bes (2004:31) inovasi berbasis desain yaitu inovasi yang dilakukan dimana produk, isi, atau kemasan dan ukuran yang dijual sama tetapi desain atau tampilannya dimodifikasi.

Inovasi keempat yang dilakukan yaitu inovasi berbasis pengembangan bahan komplementer. Pengembangan bahan komplementer yang dilakukan perusahaan Amanda Brownies dengan menambahkan bahan tambahan dan bahan pelengkap dalam proses pembuatan kue brownies untuk menghasilkan varian rasa brownies yang lebih beragam. Penambahan bahan komplementer yang digunakan disesuaikan dengan varian rasa yang akan diproduksi seperti brownies varian rasa green tea marble bahan tambahan dan pelengkap yang digunakan ekstra green tea, kismis dan kacang almond. Hal ini sesuai dengan pendapat Kotler dan De Bes (2004:31) inovasi berbasis pengembangan bahan komplementer dilakukan perusahaan dengan melibatkan penambahan bahan-bahan komplementer atau layanan tambahan atas produk atau jasa.

Inovasi produk yang dilakukan perusahaan Amanda Brownies mampu membuat perusahaan tetap berada pada siklus hidup produk tahap pertumbuhan (growth) sampai saat ini. Hal ini terbukti, produk perusahaan Amanda Brownies sampai saat masih diminati oleh konsumen dan semakin banyak konsumen yang tertarik untuk membeli, penjualan perusahaan Amanda Brownies selalu mengalami peningkatan setiap tahun sehingga keuntungan perusahaan semakin meningkat Hal ini didukung oleh pendapat Kotler dan Amstrong (2008:328) siklus hidup produk tahap pertumbuhan (growth) ditandai oleh meningkatnya penerimaan pasar dan meningkatnya keuntungan perusahaan. 
Berdasarkan hasil penelitian dilapangan menyatakan bahwa semua inovasi produk yang dilakukan perusahaan Amanda Brownies dilakukan secara bertahap artinya sedikit demi sedikit secara berkelanjutan agar produk tetap bertahan dipasaran. Inovasi yang dilakukan salah satunya dengan menambahkan varian rasa brownies agar menjadi lebih beragam. Inovasi produk yang dilakukan perusahaan Amanda Brownies mampu membuat perusahaan bertahan sampai saat ini dengan wilayah pemasaran yang semakin luas hampir di seluruh kota di Indonesia seperti membuka outlet baru di kota Jember, Situbondo dan lumajang. Hal ini sesuai dengan pendapat yang disampaikan Cristina Ariadne (2017:156) kunci untuk memperpanjang siklus hidup produk adalah melalui inovasi berkelanjutan yang dilakukan secara terus menerus sepanjang siklus hidup produk.

\section{PENUTUP}

Berdasarkan hasil penelitian dari pembahasan yang telah dipaparkan dapat disimpulkan bahwa inovasi produk yang dilakukan oleh perusahaan Amanda Brownies yaitu inovasi berbasis modulasi, inovasi berbasis kemasan, inovasi berbasis desain, dan inovasi berbasis pengembangan bahan komplementer. Adanya inovasi produk brownies yang dilakukan perusahaan Amanda Brownies mampu mempertahankan siklus hidup produk sehingga perusahaan Amanda Brownies sampai saat ini masih berada pada tahap pertumbuhan (growth) ditandai dengan produk Amanda Brownies yang semakin lama semakin diminati konsumen dan penjualan perusahaan Amanda Brownies yang selalu mengalami peningkatan setiap tahunnya, meskipun saat ini banyak perusahaan pesaing yang memproduksi produk sejenis dan tetap bertahan sampai saat ini dengan wilayah pemasaran yang semakin luas hampir di seluruh kota di Indonesia seperti Jember, Situbondo dan Lumajang.

Berdasarkan hasil penelitian, maka dapat diberikan saran kepada perusahaan Amanda Brownies yaitu perusahaan Amanda Brownies perlu mempertahankan kualitas produknya serta melakukan inovasi pada produknya secara bertahap dan berkelanjutan supaya tetap bertahan dipasaran, mengingat semakin banyaknya perusahaan pesaing yang memproduksi produk sejenis. Perusahaan Amanda Brownies juga harus memperhatikan keinginan serta kebutuhan konsumen supaya konsumen tidak meninggalkan produknya dan tetap setia menjadi pelanggan Amanda Brownies.

\section{DAFTAR PUSTAKA}

Indriani. 2006. Modern \& Classic Brownies. Jakarta: Gramedia

Kotler. P. dan F.T. De Bes. 2004. Lateral Marketing: Berbagai Teknik Baru Untuk Mendapatkan Ideide Terobosan. Alih Bahasa: Emil Salim. Jakarta: Erlangga.

Kotler. P dan G. Amstrong. 2008. Prinsip-prinsip Pemasaran. Edisi Ketigabelas. Jilid 1. Jakarta: Erlangga.

Sari, C.A. 2017. Teknik Mengelola Produk dan Merek. Jakarta: PT Gramedia Utama.

\section{Jurnal}

Hendrayanti. E. 2011. Inovasi Efektif: Upaya Mempertahankan Dan Menangkap Pasar Potensial. Jurnal Ilmu Ekonomi Manajemen Dan Kewirausahaan 5(1): 91-102. 